\title{
Análise de Integração e Contágio Financeiro na América do Sul*
}

\author{
Paulo Matos $^{\dagger}$, Amadeus Siqueira ${ }^{\ddagger}$, Nicolino Trompieri ${ }^{\S}$
}

\author{
Conteúdo: 1. Introdução; 2. Literatura relacionada; 3. Metodologia; 4. Exercício empírico; \\ 5. Conclusão. \\ Palavras-chave: Índices de Mercado, Ciclos e Tendências Comuns, América do Sul, Integração e \\ Contágio \\ Códigos JEL: G15; F21.
}

Este artigo agrega à discussão promovida em Mejía-Reyes (2000) e Hecq (2001) sobre integração e contágio financeiro nos países da América do Sul, através da modelagem de características comuns no longo e no curto prazo das trajetórias de evolução dos índices das principais bolsas de valores. Apesar da diversidade nos fundamentos macroeconômicos deste continente, os resultados sugerem os sistemas financeiros destes países não devam ser analisados individualmente, pois os desvios do equilíbrio de longo prazo em qualquer um dos mercados financeiros são capazes de influenciar os demais mercados em questão, durante o período de janeiro de 1998 e novembro de 2010. Alinhado a D'ecclesia e Costantini (2006), as evidências no curto prazo sinalizam a presença de contágio financeiro, mais evidente em razão de eventos extremos globais, positivos ou negativos, capazes de provocar oscilações de curto prazo mais acentuadas e em direções comuns, seguindo uma trajetória em que se destaca o índice peruano, cujo ciclo, imprevisível, é o único capaz de prever o ciclo comum e os demais ciclos individuais.

We enter the debate promoted by Mejía-Reyes (2000) and Hecq (2001) on financial integration and contagion in the countries of South America, based on the methodology of common characteristics in the long and short run of the major stock indexes time paths. Although this is a continent

\footnotetext{
* Primeira versão: Fevereiro de 2012. Os autores agradecem os comentários de Regis Oquendo, Ronaldo Arraes e dos participantes do Seminário de Pesquisa do CAEN/UFC, assim como do corpo editorial e dos pareceristas anônimos da Revista Brasileira de Economia. Os autores agradecem ao suporte financeiro do Programa PDE 2012 (BNDES/ANPEC). Paulo Matos agradece ao suporte do CNPq.

${ }^{\dagger}$ CAEN/UFC. Contatos para correspondência: Avenida da Universidade, $\mathrm{n}^{\circ} 2700.2^{\circ}$ andar, Bairro Benfica CEP 60.020-181 Fortaleza - Ceará, Brasil. Telefone: (85) 3366-7751. E-mail: paulomatos@caen.ufc.br

${ }^{\ddagger}$ CAEN/UFC. E-mail: amadeusbueno@yahoo.com. br

$\S$ IPECE e UNIFOR. E-mail: nicolino.trompieri@ipece.ce.gov.br
} 
with diverse economic fundamentals, our results suggest that these financial markets should not be analyzed individually, since the extent of any deviation from long-run equilibrium in one of the markets seems to be able to influence the behavior the other ones, during the period between January 1998 and November 2010. Corroborating D'ecclesia e Costantini (2006), we are able to evidence financial contagion, due to some extreme negative global events that can cause imitative behaviours in short run. We also identify the Peruvian financial market as the unique unpredictable and also the most relevant in the study of reactions to transitory shocks in South America.

\section{INTRODUÇÃO}

As economias emergentes situadas na América do Sul apresentam uma acentuada e persistente heterogeneidade em termos macroeconômicos, sociais e comerciais, apesar de um extenso histórico de tentativas de constituição de blocos desde os anos 60, a partir do pioneiro Tratado de Montevidéu.

A literatura sobre sistema financeiro e desenvolvimento, atendo-se às diferenças estruturais entre os sistemas financeiros, como em Allen e Gale (2000) e Allen et alii (2004), pode ser útil na compreensão da influência deste contexto econômico complexo e divergente nos mercados financeiros domésticos destes países, enfraquecendo-os e dificultando o processo de amadurecimento, credibilidade e confiança junto a investidores locais e estrangeiros. Como exemplo, de acordo com a análise dos volumes de transação diária em 2012 segundo a Consultoria Economatica, as 365 empresas com capital aberto no Brasil movimentaram no mercado acionário aproximadamente $0,1 \%$ do respectivo Produto Interno Bruto (PIB) anual, enquanto o movimento com as dezenas de empresas com ações na Bolsa de Valores de Colômbia (BVC) era de $0,003 \%$ do PIB colombiano. Se comparado apenas com a Bolsa de Nova Iorque (NYSE), este percentual de volume diário é de aproximadamente $0,4 \%$.

Observa-se, portanto, um cenário caracterizado pela diversidade de fundamentos econômicos, sob o qual não é trivial inferir sobre o nível de integração ou de contágio entre os mercados financeiros em questão.

Sobre esta literatura, a partir de variáveis macroeconômicas, Mejía-Reyes (2000) modela os ciclos de negócios na América Latina, através do arcabouço de cadeias Markovianas, utilizando o PIB per capita real para uma amostra contendo Argentina, Bolívia, Brasil, Chile, Colômbia, México, Peru, e Venezuela, durante o período de 1950 a 1995. O artigo não evidencia a existência de ciclos comuns nas oscilações decorrentes de expansões e contrações dessas economias, enquanto Hecq (2001), com base em três tipos de modelos de recursos cíclicos comuns: Serial Correlation Common Feature (SCCF), Weak Form reduce drank structure (WF) e o Polynomial Serial Correlation Common Features (PSCCF), conclui que Brasil, Argentina, México, Peru e Chile dividem comovimentos no longo prazo e no curto prazo, baseado em séries temporais de variáveis macroeconômicas.

Neste sentido, inicialmente este artigo aborda as relações de longo prazo, agregando, portanto, à discussão sobre integração na América do Sul, ao aplicar a metodologia de Johansen et alii (2000) e Vahid e Engle (1993) na extração de ciclos comuns e individuais dos índices de mercado de Argentina, Brasil, Chile, Colômbia, Peru e Venezuela, durante o período de janeiro de 1998 a novembro de 2010. A hipótese nula de que haja integração financeira não deriva de um arcabouço teórico, estando associada a evidências empíricas, como a convergência reportada em Matos e Landim (2011), além das contribuições de Mejía-Reyes (2000) e Hecq (2001).

Em segundo lugar, o estudo lida com as relações de curto prazo visando mensurar e identificar a direção em que os choques estão sendo transmitidos entre estes mercados financeiros. Testa-se a hipótese nula de que haja contágio financeiro, cujo mecanismo via assimetria de informação - até 
mesmo em razão da indisponibilidade ou falta de credibilidade de dados macroeconômicos na Argentina - parece ser mais relevante em economias emergentes estreitamente relacionadas comercialmente, conforme Claessens e Forbes (2004). Observe que o continente experimenta um arranjo próximo ao de uma zona de livre comércio, com desgravação tarifária para universo amplo de produtos - em alguns casos além de $90 \%$, como no da relação do MERCOSUL com o Chile. Com base em dados do Ministério das Relações Exteriores, a evolução de 2007 a 2011 do volume de importação e exportação intrabloco no MERCOSUL é de 58\%, resultado em um volume de exportações intracontinentais próximo a US\$ 100 bilhões em 2011, segundo a Associação Latino Americana de Integração (ALADI).

Em suma, os resultados sugerem que os mercados financeiros sul-americanos estabeleçam entre si uma relação de equilíbrio financeiro de longo prazo baseada em cinco tendências estocásticas comuns. No curto prazo, observa-se que as expansões transitórias possuem menor magnitude e persistência que as contrações, sendo os ciclos individuais positivamente correlacionados, com destaque para o índice de mercado peruano o qual parece ter forte poder preditivo nos demais ciclos individuais, sendo ainda o único capaz de prever o ciclo comum.

Este artigo está estruturado, de forma que na seção 2 o artigo é situado na literatura existente, enquanto a metodologia está na seção 3. Os resultados estão na quarta seção e as considerações finais estão na quinta seção.

\section{LITERATURA RELACIONADA}

Possivelmente, o interesse inicial dos economistas em usar um arcabouço estatístico capaz de decompor séries não estacionárias em componentes permanentes e transitórios tenha sido com relação ao estudo da evolução das riquezas de nações ou setores, além da trajetória de consumo e renda, visando testar empiricamente implicações teóricas, como a teoria da renda permanente, por exemplo. Assim, algumas técnicas utilizadas para identificar tais componentes em séries temporais usando cointegração e tendências comuns seguem Granger e Weiss (1983), Engle e Granger (1987), Stock e Watson (1988), Engle (1997), além de características comuns no sentido de Engle e Kozicki (1993), ou ainda codependência, como em Gourieroux et alii (1991).

Na teoria financeira, a aplicação destas técnicas parece ser mais recente e não necessariamente se baseia em uma teoria microfundamentada sobre o nível de integração ou de contágio financeiro entre países, sobre a eficiência dos mercados financeiros ou mesmo relacionado à diversificação de risco internacional.

Neste estudo, inicialmente em termos de longo prazo, o que se pretende compreender é se os retornos acumulados dos principais índices de mercado da América do Sul possuem trajetórias que se movem conjuntamente ao longo do tempo, de forma que se possa evidenciar ou não se as séries cointegram, ou seja, se há tendências estocásticas comuns implicando em uma relação de equilíbrio de longo prazo entre estes índices. A interpretação associada à existência de vetores cointegrantes que formalizem essa relação de longo prazo, assim como em estudos de convergência de longo prazo em indicadores financeiros, pode ser útil no sentido de inferir sobre integração financeira dos mercados financeiros representados pelas séries temporais em questão.

Neste contexto, satisfazendo parcialmente as críticas em Kose et alii (2006) e Henry (2007), este artigo agrega à literatura sobre integração que recorre a diferentes técnicas, como Antzoulatos et alii (2011) e Matos e Landim (2011) que aplicam a técnica de convergência semiparamétrica desenvolvida por Phillips e Sul (2007) para variáveis financeiras em amplos cross-sections de países, ou Fürstenberg e Jeon (1989), Bianco et alii (1997) e Schmidt et alii (2001) que estudam empiricamente a convergência em amostras contendo somente economias desenvolvidas, ou pertencentes ao mercado comum europeu. ${ }^{1}$

\footnotetext{
${ }^{1}$ Kose et alii (2006) e Henry (2007) criticam as divergências nas evidências, associando-as à diversidade dos trabalhos sobre integração financeira em relação à amostra de países, ao período de análise, à metodologia econométrica e às variáveis adotadas como proxy de integração financeira.
} 
Essa análise sobre o padrão comum de longo prazo na evolução dos indicadores financeiros pode ser acompanhado da identificação de outras características comuns no sentido de Engle e Kozicki (1993). Dentre outras características usualmente observadas, a presença de ciclos comuns implica na existência de uma combinação linear das primeiras diferenças não previsível, sendo útil no sentido de mensurar se há algum contágio entre os mercados financeiros. Visando agregar a este debate de contágio em mercados financeiros, bem explorado conceitualmente em Claessens e Forbes (2004) e testado empiricamente em Chan-Lau et alii (2004), extrai-se, seguindo Vahid e Engle (1993), o ciclo individual de cada bolsa de valores, assim como o ciclo comum, caso haja, sendo possível recorrer à Causalidade de Granger, com o intuito de inferir sobre a influência dos desvios temporários da trajetória de equilíbrio de cada mercado financeiro nos demais mercados.

Em aplicações metodologicamente alinhadas a este artigo, como Dempster et alii (2000), Hecq et alii (2000), Morley e Pentecost (2000), Sharma e Wongbangpo (2002) e Westermann (2002), os resultados de comovimentos de curto e longo prazos comuns entre ações ou índices de mercado transacionados em diferentes economias são utilizados com fins de análise de integração financeira, eficiência ou mesmo visando inferir sobre que mercados financeiros são mais influentes em grupos específicos de países.

Mais recentemente, D'ecclesia e Costantini (2006) discutem aspectos relacionados à diversificação internacional associada a um portfolio composto pelos índices das principais bolsas de valores do mundo, situadas no Canadá, nos Estados Unidos, no Japão e no Reino Unido, sendo a evidência de um único ciclo comum interpretada como um indício de baixo poder de diversificação no curto prazo.

\section{METODOLOGIA}

\subsection{Estacionariedade e mudança estrutural das séries de retorno acumulado}

Algumas séries temporais podem ser classificadas como estacionárias, cuja intuição está associada à oscilação em torno de uma média constante, ou mais formalmente, por estas possuírem função de distribuição de probabilidade cujos momentos independem do tempo. Esta é uma classificação comum em séries de retorno, porém não em séries de cotações de ativos financeiros. Como séries temporais de ganhos acumulados carregam algumas das características estatísticas das séries de cotações, as séries analisadas neste estudo podem não ser estacionárias. Neste caso, a série de evolução do ganho de um investidor local no principal índice de mercado do seu próprio país oscilaria em torno de uma tendência, determinística ou estocástica.

Em razão da necessidade de se identificar essa natureza das séries em questão, e se for o caso, a natureza da tendência, o primeiro aspecto metodológico consiste em implementar os testes de estacionariedade.

Inicialmente, visando obter resultados robustos à mudança de técnica, uma vez que cada uma se mostra mais adequada em razão do poder do teste, da presença de autocorrelação serial ou heterocedasticidade dos resíduos, além da sensibilidade ao tamanho da mostra, faz-se uso de cinco diferentes especificações de testes de estacionariedade:

i) a versão aumentada (ADF) do teste originalmente proposto em Dickey e Wayne $(1979,1981)$;

ii) o arcabouço semiparamétrico sugerido em Phillips e Perron (1988);

iii) o teste KPSS proposto em Kwiatkowski et alii (1992);

iv) o método desenvolvido em Elliot, Rothemberg e Stock (1996);

v) o teste proposto em Perron e Ng (1996). Os resultados desses testes são apresentados na subseção 4.2 . 
Em razão do período de tempo analisado apresentar mudanças visuais acentuadas nas séries, decorrente da recente crise financeira, dentre outras, são apresentados os principais resultados sobre estacionariedade associados a outros dois testes de raiz unitária, ambos robustos à presença de quebra estrutural, o que pode viesar os resultados dos testes tradicionais já citados. ${ }^{2}$

Assim, seguindo Evans (1989), Perron e Vogelsang (1991), Christiano (1992), Zivot e Andrews (1992), Banerjee et alii (1992) e Leybourne et alii (1998), uma primeira possibilidade de lidar com este aspecto se baseia na hipótese de que as quebras estejam associadas a realizações extremas da série de retorno do ativo, devendo ser modeladas endogenamente no teste de estacionariedade. Neste sentido, implementa-se a metodologia proposta em Zivot e Andrews (1992), cuja hipótese nula é de ausência de quebra estrutural. Sob a hipótese alternativa, em que há quebras, este teste agrega ao arcabouço de Perron (1989) ao inserir um algoritmo que permite a identificação endógena das quebras estruturais.

A segunda vertente está alinhada a artigos, como Perron (1989), Park e Sung (1994), Lütkepohl, Müller e Saikkonen (2001) e Saikkonen e Lütkepohl $(2001,2002)$. Esta linha analisa esta questão sob a premissa de se optar pela exogeneidade da escolha dos pontos de quebra, segundo algum critério estatístico de identificação da data da quebra ou a partir da associação com um evento considerado como um choque exógeno de natureza econômica relevante o suficiente. Seguindo esta vertente, implementa-se o teste de estacionariedade de Saikkonen e Lütkepohl (2002), com a inserção exógena do mês da quebra estrutural identificada endogenamente através do teste de Chow, em acordo com Candelon e Lutkepohl (2001).

\subsection{Cointegração, tendências e ciclos individuais das séries de retorno acumu- lado}

\subsubsection{Decomposição individual de uma série temporal não estacionária}

Séries temporais não estacionárias podem ser decompostas em uma tendência, um termo estacionário e um ruído, de forma que se possa analisar especificamente estes componentes, tornando possível mensurar se o componente estacionário suaviza ou acentua os choques de longo prazo, ou mesmo visando detalhar a natureza da tendência, por exemplo, se determinística ou estocástica, o que é importante para o uso da metodologia adequada visando obter séries estacionárias.

Formalmente, seguindo Beveridge e Nelson (1981), é possível decompor linearmente cada uma das séries temporais de retorno nominal bruto acumulado do índice de mercado da economia $i$ sob a ótica do investidor local, $R_{t}^{i}, t=0,1,2, \ldots, T$ da seguinte forma: ${ }^{3}$

$$
R_{t}^{i}=P_{t}^{i}+C_{t}^{i}
$$

Nesta relação, $P_{t}^{i}$ consiste em um componente permanente, na forma de um passeio aleatório com drift, cuja interpretação está associada à previsão de longo prazo da série ajustada em relação à tendência determinística. O segundo termo, $C_{t}^{i}$, é um componente estacionário, dito transitório ou cíclico, que se dá na forma de uma combinação linear não convexa dos resíduos contemporâneo e passados e que intuitivamente capta os efeitos de curto prazo do respectivo índice de mercado. ${ }^{4}$ A relação (1) pode ser reescrita da seguinte forma:

$$
R_{t}^{i}=P_{t}^{i}+C_{t}^{i}=P_{t-1}^{i}+\delta^{i}+\psi^{i}(1) \varepsilon_{t}^{i}+\psi^{* i}(L) \varepsilon_{t}^{i}
$$

\footnotetext{
${ }^{2}$ Ver Enders (2010) para exemplos e maiores detalhes sobre esta questão.

${ }^{3}$ Existem várias formas de se decompor uma série não estacionária em componentes estacionários e não estacionários. No entanto, a decomposição de Beveridge e Nelson (1981) chama especial atenção em estudos empíricos sobre renda, pois uma tendência na forma de um passeio aleatório está relacionada ao conceito de renda permanente.

${ }^{4}$ Para que o componente cíclico de um processo não estacionário autoregressivo de médias móveis, $A R I M A(p, d, q)$ seja estacionário é suficiente impor a restrição de que não seja infinito o somatório ponderado do valor absoluto dos parâmetros da média móvel, $M A(q)$. Maiores detalhes, ver Bueno (2011).
} 
Nesta segunda relação, os termos que compõem o componente permanente são: $\varepsilon^{i}$, que é o drift da tendência, $\psi^{i}(1)$, que consiste no somatório dos parâmetros de um operador $L$ de defasagens específico do ativo $i$ e $\varepsilon_{t}^{i}$ que é o resíduo do índice $i$ no período $t$. O componente cíclico é composto apenas pelo operador $\psi^{* i}(L)$, que é uma adaptação do operador de defasagens $\psi^{i}(L)$, aplicado aos resíduos.

\subsubsection{Análise da cointegração em séries temporais não estacionárias}

Dispondo-se de um sistema de séries, o interesse pode estar associado não somente à análise individual, mas também conjunta. Engle e Kozicki (1993) agregam a esta literatura, apresentando formalmente o conceito de característica comum às séries do sistema, cuja intuição está associada à possibilidade de que esta característica, necessariamente presente em cada uma das séries, não apareça em uma combinação linear não nula destas séries. Dependendo da estacionariedade das séries e da própria natureza das variáveis em questão, o interesse pode ser em lidar com a sazonalidade, a heterocedasticidade ou a correlação serial presente nas séries temporais.

Neste contexto, é usual estudar em séries não estacionárias se seus componentes individuais estão relacionados, de forma que as séries não possam se movimentar independentemente uma das outras. Essa análise do movimento conjunto de séries não estacionárias com ordem de integração I(1), dita cointegração, pode ser associada ao estudo de características comuns, a partir do interesse em evidenciar se as séries compartilham de tendência estocástica comum, de forma que haja uma projeção linear destas séries, tal que seja estacionária. ${ }^{5}$

A formalização visando evidenciar a existência desta relação de longo prazo entre as séries de ganho acumulado se dá através da identificação do vetor (não nulo) de cointegração, o qual é capaz de propiciar uma combinação linear estacionária das séries, ou seja, uma combinação dos componentes cíclicos das séries.

Havendo $N=6$ séries no sistema aqui analisado, pode haver no máximo $N-1=5$ vetores cointegrantes, linearmente independentes. A quantidade desses vetores que eliminam a presença de tendência é identificada por $r$, os quais podem ser arranjados matricialmente em $\alpha_{(N \times r)}$, cujo subespaço vetorial do $\mathbb{R}^{N}$ gerado é dito espaço de cointegração. Dentre as metodologias de cointegração existentes, opta-se aqui pela metodologia multivariada sugerida em Johansen et alii (2000), o qual controla 0 efeito de variáveis defasadas, além de se mostrar robusto à inserção exógena de uma mesma quebra estrutural para todas as séries, no sentido de Chow, por exemplo. A especificação é adotada de forma que a quantidade de defasagens siga o critério de Schwarz, considerando-se intercepto e tendência. Os resultados deste teste e os respectivos vetores cointegrantes estão na subseção 4.3.

\subsubsection{Análise de ciclos comuns em séries temporais não estacionárias}

Observando o mesmo sistema com os seis índices sul-americanos, seguindo Vahid e Engle (1993), é possível explorar outra característica comum: a correlação serial nas séries em primeira diferença. Ou seja, pode haver no máximo $N-1=5$ vetores cocaracterísticos, linearmente independentes, os quais identificam uma combinação linear das séries de ganho acumulado em primeira diferença a qual consiste em uma inovação em relação ao conjunto de informação passada. A quantidade desses vetores é dada por $s$, os quais podem ser arranjados matricialmente em $\check{\alpha}_{(N \times s)}$, cujo subespaço vetorial do $\mathbb{R}^{N}$ gerado é dito espaço cocaracterístico.

Segundo Vahid e Engle (1993), uma implicação da evidência da correlação serial como característica comum nas séries em primeira diferença é a existência de ciclo comum nas séries em nível. Ou seja, a mesma transformação que elimina a correlação serial nas séries em primeira diferença, quando aplicada às séries em nível também elimina o componente cíclico. Logo, as combinações cocaracterísticas são combinações lineares das tendências das séries. Uma forma intuitiva de se identificar isso é através

\footnotetext{
${ }^{5} \mathrm{~A}$ ordem de integração de uma série consiste na quantidade necessária de diferenciações visando obter uma série estacionária. Esta ordem está relacionada diretamente á quantidade de somatórios dos erros na versão recursiva da série não estacionária.
} 
da decomposição de Stock e Watson (1988), versão matricial da decomposição de Beveridge e Nelson (1981), segundo a qual,

$$
\Delta R_{t}=\delta+\psi(1) \Sigma_{j=1}^{t} \varepsilon_{j}+\psi^{*}(L) \varepsilon_{t}
$$

Nesta relação, $\Delta R_{t}$ é o vetor $N \times 1$ dos retornos acumulados em primeira diferença, $\delta$ é o vetor $N \times 1$ de drift, $\varepsilon_{j}$ é vetor $N \times 1$ de resíduos no período $j$ e $\psi(1)$ é uma matriz polinomial do operador $L$ de defasagens que pode ser decomposto linearmente como a soma $\psi(1)+(1-l) \psi^{*}(L)$.

Atendo-se às relações de longo prazo na decomposição (3), a quantidade de vetores cointegrantes é dada por $r=N-k$, onde $k$ é o posto da matriz $\psi(1)$. Logo, não havendo posto completo, $\exists \alpha$ tal que, $\alpha^{\prime} \psi(1)=0$. Analogamente, a existência dos vetores cocaracterísticos depende se todas as matrizes em $\psi^{*}(L)$ não possuem posto completo. É possível relacionar essas caraterísticas comuns de curto e de longo prazo. Havendo $r$ vetores cointegrantes, então caso haja vetores cocaracterísticos, a quantidade máxima destes é dada por $s \leq N-r$. Neste caso, $\exists \check{\alpha}$ tal que, $\check{\alpha}^{\prime} \psi^{*}(L)=0$. Em suma, a partir desta decomposição, tem-se que as colunas das matrizes $\alpha$ e $\check{\alpha}$ respectivamente, são os autovetores associados aos autovalores nulos e unitários do polinômio matricial $\psi(1)^{\prime}{ }^{6}$

As séries temporais das tendências e ciclos comuns estão reportadas nas subseções 4.5 e 4.6.

Como o processo de identificação da quantidade de vetores cointegrantes e vetores cocaracterísticos e a consequente caracterização destes se dá através da estimação paramétrica via máxima verossimilhança aplicada ao modelo de vetor correção de erros (VECM) - modelagem similar ao Auto-Regressão Vetorial (VAR), porém com o acréscimo do erro de equilíbrio em razão da evidência acerca da não estacionariedade das séries individuais de ganho acumulado, as estimações do VECM são apresentadas na subseção 4.3 .

\subsubsection{Análise de tendências e ciclos individuais em séries temporais não estacionárias}

Há um caso especial, o qual se evidencia como válido neste exercício, em que há $r>0$ vetores cointegrantes linearmente independentes e exatamente $s=6-r$ vetores cocaracterísticos linearmente independentes, sendo possível obviamente gerar o $\mathbb{R}^{6}$. Neste caso, a matriz $A_{(N \times N)}=\left[\begin{array}{c}\check{\alpha}^{\prime} \\ \alpha\end{array}\right]$ possui posto completo, sendo sua inversa, dada por $A^{-1}$, a qual pode ser particionada da seguinte forma: $A^{-1}=\left[\check{\alpha}^{-} \mid \alpha^{-}\right] .^{7}$ Esta notação é útil para que se possa reescrever a relação (2), no sentido de se caracterizar as tendências e ciclos individuais, da seguinte forma:

$$
R_{t}=P_{t}+C_{t}=\check{\alpha}^{-} \check{\alpha}^{\prime} R_{t}+\alpha^{-} \alpha R_{t}
$$

Comparando estas relações, o componente permanente de cada índice é função dos vetores cocaracterísticos, enquanto os componentes cíclicos dependem apenas das combinações cointegrantes.

A análise sobre as tendências e ciclos individuais está na subseção 4.4 .

\section{EXERCÍCIO EMPÍRICO}

\subsection{Base de dados e estatísticas descritivas}

O melhor cenário para a condução de uma pesquisa empírica, em termos de base de dados, é dispor de observações desagregadas, com distintas frequências, dispostas em séries temporais longas para amplos cortes transversais de dados. No caso específico da América do Sul, diferentemente do continente

\footnotetext{
${ }^{6}$ Neste artigo, o teste de ciclos comuns segue Vahid e Engle (1993), atendo-se especificamente à rotina sugerida em Warne (2008).

${ }^{7}$ Proietti (1997) demonstra ser factível a decomposição, mesmo quando a soma de vetores cointegrantes e cocaracterísticos é menor que $N$.
} 
europeu onde a maioria das bolsas possui índices transacionados há mais de duas décadas, observase um mercado financeiro menos desenvolvido e com menos bolsas de valores. Consequentemente, dispõe-se de uma quantidade reduzida de índices de mercado considerados tradicionais ou com reconhecida relevância no cenário internacional, sendo esta uma limitação imposta a artigos empíricos que lidem com este continente.

Diante deste dilema, em razão do intuito de analisar ciclos e tendências comuns aos principais índices financeiros transacionados nos países sul-americanos sob distintos cenários macroeconômicos e sob a premissa da relevância do volume de transação e da abrangência na composição, sugere-se aqui fazer uso dos principais índices de mercado das economias brasileira, colombiana, argentina, venezuelana, peruana e chilena. Os índices são os seguintes:

i) Sao Paulo Stock Exchange Index (IBOVESPA), no Brasil;

ii) Colombia Stock Exchange General Index (IGBC), na Colômbia;

iii) Buenos Aires Stock Exchange Merval Index (MERVAL), na Argentina;

iv) Caracas Stock Exchange General Index (IBVC), na Venezuela;

v) Lima Stock Exchange General Index (IGBVL), no Peru;

vi) Santiago Stock Exchange IPSA Index (IPSA), no Chile.

O uso deste sistema de índices, sobre o qual se testa a hipótese nula de contágio e integração, é útil na identificação dos componentes individuais estacionários ou não de cada série, além de permitir a análise conjunta, a qual se traduz na inserção de restrições de alta e baixa frequência no processo de identificação de choques transitórios e permanentes, agregando ao proporcionar maior eficiência e ao ponderar corretamente a relevância dos choques permanentes e transitórios nas dinâmicas de curto e longo prazo. Maiores detalhes sobre esse ganho de eficiência, ver Issler e Vahid (2001).

A série temporal compreende o período de janeiro de 1998 a novembro de 2010, em um total de 155 observações de retornos líquidos nominais mensais. A fonte dos dados é a CMA Trade.

As características e os respectivos códigos destes índices são descritos na Tabela 1.

Tabela 1: Descrição dos índices de mercado dos países da América do Sul

\begin{tabular}{lccc}
\hline \multicolumn{1}{c}{ Índice } & Código & Cidade/País & $\begin{array}{c}\text { Ano de } \\
\text { construção do } \\
\text { índice }\end{array}$ \\
\hline Sao Paulo Stock Exchange Index & IBOVESPA & São Paulo/ Brasil & 1968 \\
Colombia Stock Exchange General Index & IGBC & Bogotá/ Colômbia & 2001 \\
Buenos Aires Stock Exchange Merval Index & MERVAL & Buenos Aires/ Argentina & 1986 \\
Caracas Stock Exchange General Index & IBVC & Caracas/ Venezuela & 1987 \\
Lima Stock Exchange General Index & IGBVL & Lima/ Peru & 1981 \\
Santiago Stock Exchange IPSA Index & IPSA & Santiago/ Chile & 1977 \\
\hline
\end{tabular}

Apesar de a metodologia do cálculo do IGBC ter sido oficializada somente em 2001, a série de retornos deste índice está disponível no Economática desde 02 de janeiro de 1991, com a fusão das bolsas de Medelín, Bogotá e Ocidente. 
Os índices são distintos em relação à maturidade, sendo o mais tradicional deles o IBOVESPA, cujo ano de construção data de 1968, enquanto o índice colombiano é transacionado há um pouco mais de uma década. A maioria dos índices teve sua metodologia proposta nas décadas de 70 e 80 e, exceto pelo MERVAL cuja composição depende apenas do preço das ações, todos possuem rebalanceamento baseado em uma composição ponderada pela capitalização de mercado das ações.

A Figura 1 reporta a evolução do retorno mensal bruto nominal acumulado sob a ótica do investidor local, ou seja, sem que se modele o risco cambial, durante o período aqui analisado.

Figura 1: Evolução do ganho acumulado dos índices de mercado dos países da América do Sul

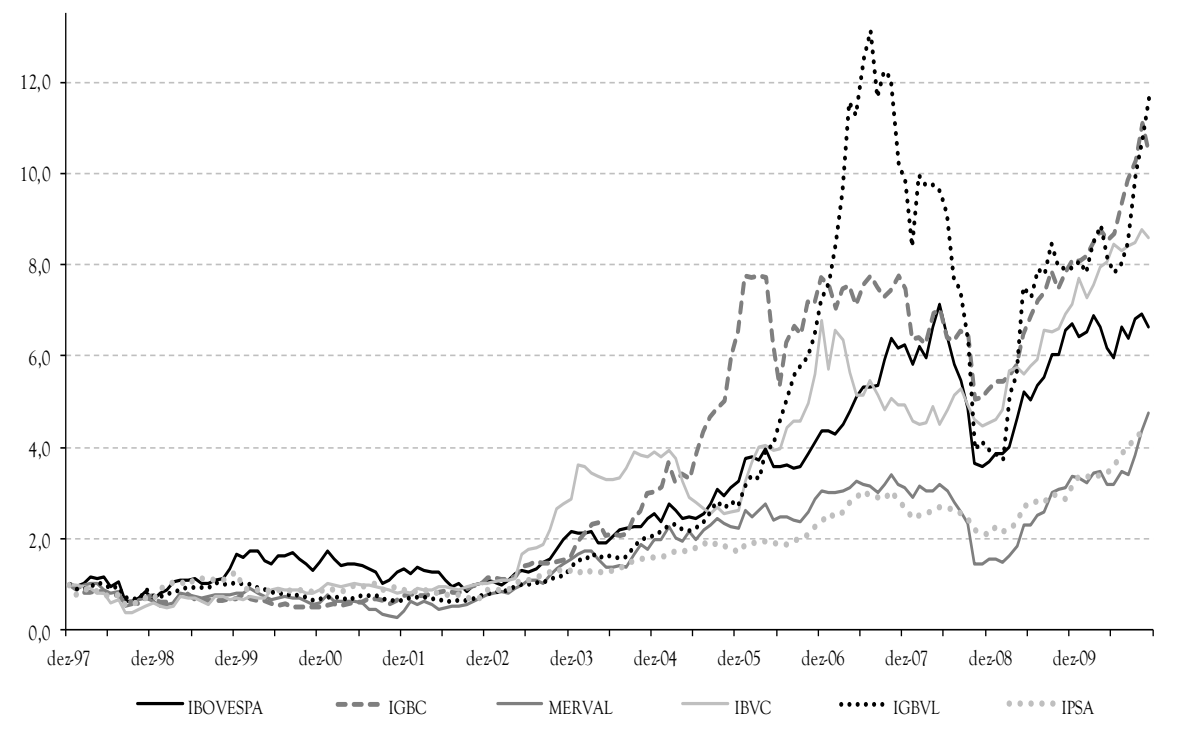

Retorno nominal acumulado mensal de cada índice de mercado, durante o período de janeiro de 1998 até novembro de 2010 , totalizando 155 observações.

Fonte: CMA Trade.

É possível evidenciar uma maior proximidade entre os índices MERVAL e IPSA, ambos seguindo trajetórias que caracterizam uma envoltória inferior aos demais índices a partir de 2004, além de um acentuado deslocamento superior do IGBVL de 2007 a 2008 e uma aparente convergência ao final do período deste índice com IBOVESPA, IGBC e IBVC. As respostas à crise não parecem similares, com uma reação antecipada e de maior intensidade do IGBVL, cuja queda acumulada é de $71,51 \%$, seguido do MERVAL, com uma queda da mesma ordem de grandeza, enquanto o índice chileno reage de forma mais suave. Há um comportamento contra intuitivo do índice venezuelano, o qual apresenta quedas sucessivas já no primeiro semestre de 2007, antes mesmo do estopim da crise, seguido de ganhos significativos em um curto período de tempo, durante o qual, são evidenciadas as maiores quedas na maioria dos índices no mundo.

Analisando as trajetórias de recuperação após a crise, de março de 2009 até o final do período amostral, quando os retornos mensais são sistematicamente positivos, os maiores ganhos acumulados estão associados ao MERVAL, com quase 190\% e o IGBVL, com 125\%, justamente os índices que apresentaram as maiores quedas acumuladas. Mesmo apresentando a menor queda acumulada, 45,20\%, o IPSA apresentou a terceira melhor recuperação, com quase $100 \%$ de ganho líquido acumulado ao final do período analisado.

Ao longo de todo o período amostral, o índice peruano apresenta o maior ganho acumulado, 1.067,21\%, enquanto o MERVAL proporciona ganho de apenas $374,37 \%$. $O$ índice argentino está associado ainda aos 
maiores níveis de risco, com base em todas as métricas, exceto pelo drawdown, cuja ordem de grandeza é bem próxima à observada para o IGBVL. O índice robustamente menos volátil é o IPSA do Chile. Os índices possuem assimetrias em direções distintas, porém em baixas magnitudes e todos apresentam leptocurtose, com maior magnitude para o IPSA. Algumas das principais estatísticas descritivas destes índices estão reportadas na Tabela 2.

Tabela 2: Estatísticas descritivas dos retornos dos índices de mercado dos países da América do Sul

\begin{tabular}{|c|c|c|c|c|c|c|c|}
\hline \multicolumn{2}{|c|}{ Métrica/ Índice } & \multirow{2}{*}{$\begin{array}{c}\text { IBOVESPA } \\
1,67 \%\end{array}$} & \multirow{2}{*}{$\begin{array}{c}\text { IGBC } \\
1,86 \%\end{array}$} & \multirow{2}{*}{$\begin{array}{c}\text { MERVAL } \\
1,65 \%\end{array}$} & \multirow{2}{*}{$\begin{array}{c}\text { IBVC } \\
1,88 \%\end{array}$} & \multirow{2}{*}{$\begin{array}{l}\text { IGBVL } \\
2,03 \%\end{array}$} & \multirow{2}{*}{$\begin{array}{c}\text { IPSA } \\
1,22 \%\end{array}$} \\
\hline & médio & & & & & & \\
\hline & mínimo & $-39,55 \%$ & $-21,87 \%$ & $-39,11 \%$ & $-42,37 \%$ & $-37,28 \%$ & $-29,86 \%$ \\
\hline \multirow[t]{2}{*}{ Ganho } & máximo & $24,05 \%$ & $26,49 \%$ & $48,68 \%$ & $48,29 \%$ & $38,46 \%$ & $33,17 \%$ \\
\hline & acumulado líq. & $564,03 \%$ & $943,22 \%$ & $374,37 \%$ & $758,31 \%$ & $1067,21 \%$ & $337,99 \%$ \\
\hline \multirow{3}{*}{ Risco } & desvio padrão & $9,23 \%$ & $8,30 \%$ & $11,44 \%$ & $9,99 \%$ & $9,28 \%$ & $7,13 \%$ \\
\hline & semivariância & $6,92 \%$ & $5,83 \%$ & $7,77 \%$ & $6,31 \%$ & $6,37 \%$ & $5,17 \%$ \\
\hline & drawdown & $51,62 \%$ & $50,22 \%$ & $71,49 \%$ & $62,30 \%$ & $71,51 \%$ & $45,20 \%$ \\
\hline $3^{\circ}$ e $4^{\circ}$ & assimetria & $-0,67$ & 0,01 & 0,39 & 0,71 & 0,13 & $-0,35$ \\
\hline momentos & curtose & 5,04 & 3,67 & 6,67 & 8,50 & 6,63 & 8,92 \\
\hline
\end{tabular}

Estatísticas obtidas a partir das séries mensais de retornos líquidos nominais de cada índice de mercado sob a ótica do investidor local, ou seja, sem ajuste cambial, durante o período de janeiro de 1998 até novembro de 2010.

Fonte: CMA Trade.

\subsection{Estacionariedade e mudança estrutural das séries de retorno acumulado}

Uma análise visual da Figura 1, a qual não permite fazer inferências estatísticas a priori, sugere que as séries temporais de evolução dos ganhos acumulados possuam tendências individuais e que as séries sejam caracterizadas por mudanças de comportamento associadas a uma ou mais quebras estruturais em razão da crise financeira.

Neste sentido, inicialmente são reportados os resultados dos testes de estacionariedade na Tabela 3.

Os testes preliminares, cujos resultados não são robustos à presença de quebras estruturais, sugerem, conforme se observa no Painel A desta tabela, que todas as séries de ganho acumulado dos principais índices de mercado na América do Sul não sejam estacionárias, com uma única e pontual exceção. O índice peruano, com base apenas no teste proposto em Elliot, Rothemberg e Stock (1996) se mostra estacionário a um nível de significância de 5\%. A natureza da não estacionariedade, se associada a tendências determinísticas ou estocásticas e a consequente ordem de integração das séries dependem dos resultados obtidos para as mesmas séries em $1^{\mathrm{a}}$ diferença. Com base em todos os testes, todos os seis índices parecem ser estacionários em $1^{\text {a }}$ diferença, caracterizando a presença de raiz unitária associada à presença de tendência individual estocástica.

Visando lidar com a possibilidade de mudança de regime ao longo do tempo, implementa-se o teste estatístico de Chow, baseado na distribuição $\mathrm{F}$, o qual compara as estimativas das variâncias dos resíduos de um modelo com parâmetros constantes com as respectivas estimativas, porém de um modelo que permite uma mudança nos parâmetros, verificando se as diferenças nas estimativas antes e depois do referido mês são estatisticamente significantes. Este teste identifica setembro de 2008 como o único mês em que há mudança estrutural no modelo, havendo instabilidade antes dessa data e estabilidade após. Este resultado é incorporado de forma exógena ao arcabouço de Saikkonen e Lütkepohl (2002), cujos resultados estão reportados no Painel $C$.

No Painel B, estão os resultados do teste que incorpora endogenamente a possibilidade de quebras estruturais, proposto em Zivot e Andrews (1992). Observa-se que as evidências prévias são corroboradas quando os testes incorporam quebras estruturais endógena e exogenamente. 
Todos os resultados sugerem que as séries de ganho acumulado não sejam estacionárias em nível, mas sim em $1^{a}$ ordem, resultado robusto à inserção ou não de quebra estrutural, assim como robusto às mudanças de especificações nos testes, em termos de:

i) expansão na quantidade máxima de defasagens e identificação da quebra na constante e/ou na tendência no teste proposto em Zivot e Andrews (1992);

ii) inserção de constante e/ou tendência nos testes tradicionais no Painel A;

iii) consideração de quebra estrutural endógena no teste de Saikkonen e Lütkepohl (2002).

Tabela 3: Estacionariedade dos retornos acumulados dos índices de mercado dos países da América do Sul

\begin{tabular}{|c|c|c|c|c|c|c|c|}
\hline \multirow{2}{*}{\multicolumn{8}{|c|}{ 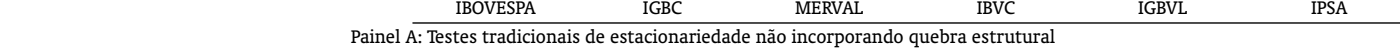 }} \\
\hline & & & & & & & \\
\hline Augmented Dickey-Fuller b & Teste em nível & $-2,45[0,35]$ & $-1,80[0,70]$ & $-1,82[0,69]$ & $-2,00[0,60]$ & $-2,86[0,18]$ & $-0,20[0,99]$ \\
\hline (HO: Série com raiz unitária) & $\begin{array}{c}\text { Teste na } \\
1^{\mathrm{a}} \text { diferença }\end{array}$ & $-10,29^{* * *}[0,00]$ & $-10,51^{* * *}[0,00]$ & $-10,30^{* * * *}[0,00]$ & $-12,27^{* * *}[0,00]$ & $-5,56^{* * *}[0,00]$ & $-10,63^{* * * *}[0,00]$ \\
\hline Phillips e Perron (1988) C & Teste em nível & $-2,45[0,35]$ & $-1,92[0,64]$ & $-1,90[0,65]$ & $-2,26[0,45]$ & $-2,14[0,52]$ & $-0,82[0,96]$ \\
\hline (HO: Série com raiz unitária) & $\begin{array}{c}\text { Teste na } \\
1^{\mathrm{a}} \text { diferença }\end{array}$ & $-10,40^{* * * *}[0,00]$ & $-10,46^{* * *}[0,00]$ & $-10,47^{* * * *}[0,00]$ & $-12,32^{* * *}[0,00]$ & $-10,71^{* * * *}[0,00]$ & $-10,75^{* * * k}[0,00]$ \\
\hline $\begin{array}{l}\text { Kwiatkowski-Phillips } \\
\text { Schmidt-Shin (1992) d }\end{array}$ & Teste em nível & $0,24^{* * * *}$ & $0,18^{* *}$ & $0,14^{* *}$ & $0,17^{* *}$ & $0,16^{* *}$ & $0,26^{* * *}$ \\
\hline (H0: Série estacionária) & $\begin{array}{c}\text { Teste na } \\
1^{\mathrm{a}} \text { diferença }\end{array}$ & 0,03 & 0,07 & 0,07 & 0,04 & 0,04 & 0,06 \\
\hline $\begin{array}{l}\text { Elliott et alii (1996) e } \\
\text { (H0: Série com raiz unitária) }\end{array}$ & $\begin{array}{l}\text { Teste em nível } \\
\text { Teste na } \\
1^{\mathrm{a}} \text { diferença }\end{array}$ & $\begin{array}{l}12,47 \\
1,35^{* * *}\end{array}$ & $\begin{array}{l}30,42 \\
1,66^{* * * *}\end{array}$ & $\begin{array}{c}16,54 \\
1,66^{* * *}\end{array}$ & $\begin{array}{l}25,85 \\
1,26^{* * *}\end{array}$ & $\begin{array}{l}5,11^{* * *} \\
2,54^{\text {**** }}\end{array}$ & $\begin{array}{l}39,46 \\
1,42^{* * *}\end{array}$ \\
\hline $\begin{array}{l}\text { Perron e Ng (1996) f } \\
\text { (H0: Série com raiz unitária) }\end{array}$ & $\begin{array}{l}\text { Teste em nível } \\
\text { Teste na } \\
1^{\text {a }} \text { diferença }\end{array}$ & $\begin{array}{l}\text { H0: Não Rejeição } \\
\text { H0: Rejeição a 1\% }\end{array}$ & $\begin{array}{l}\text { H0: Não Rejeição } \\
\text { H0: Rejeição a 1\% }\end{array}$ & $\begin{array}{l}\text { H0: Não Rejeição } \\
\text { H0: Rejeição a 1\% }\end{array}$ & $\begin{array}{l}\text { H0: Não Rejeição } \\
\text { H0: Rejeição a 1\% }\end{array}$ & $\begin{array}{l}\text { H0: Não Rejeição } \\
\text { H0: Rejeição a 1\% }\end{array}$ & $\begin{array}{l}\text { HO: Não Rejeição } \\
\text { H0: Rejeição a } 1 \%\end{array}$ \\
\hline \multicolumn{8}{|c|}{ Painel B: Teste de estacionariedade incorporando quebra estrutural endógena } \\
\hline $\begin{array}{l}\text { Zivot-Andrews (1992) g } \\
\text { (H0: Série com raiz unitária } \\
\text { considerando quebra } \\
\text { estrutural endógena) }\end{array}$ & $\begin{array}{l}\text { Teste em nível } \\
\text { Teste na } \\
1^{\text {a }} \text { diferença }\end{array}$ & $\begin{array}{c}-3,39 \\
-10,70^{* * *}\end{array}$ & $\begin{array}{c}-3,11 \\
-11,24^{* * *}\end{array}$ & $\begin{array}{c}-3,97 \\
-10,77^{* * *}\end{array}$ & $\begin{array}{c}-3,08 \\
-12,85^{* * * *}\end{array}$ & $\begin{array}{l}-4,09 \\
-5,71^{* * * *}\end{array}$ & $\begin{array}{c}-2,96 \\
-11,00^{* * *}\end{array}$ \\
\hline \multicolumn{8}{|c|}{ Painel C: Teste de estacionariedade incorporando quebra estrutural exógena } \\
\hline $\begin{array}{l}\text { Saikkonen-Lütkepohl (2002) h } \\
\text { (H0: Série com raiz unitária } \\
\text { considerando quebra estrutural } \\
\text { exógena em setembro de 2008) }\end{array}$ & $\begin{array}{l}\text { Teste em nível } \\
\text { Teste na } \\
1^{\text {a }} \text { diferença }\end{array}$ & $\begin{array}{c}-2,07 \\
-10,12^{* * * *}\end{array}$ & $\begin{array}{c}-1,7 \\
-10,24^{* * *}\end{array}$ & $\begin{array}{l}-2,38 \\
-9,61^{* * *}\end{array}$ & $\begin{array}{c}-1,9 \\
-12,23^{\text {**** }}\end{array}$ & $\begin{array}{l}-2,96 \\
-5,61^{* * *}\end{array}$ & $\begin{array}{c}-1,5 \\
-10,21^{* * *}\end{array}$ \\
\hline
\end{tabular}

Testes de estacionariedade aplicados às séries de retornos acumulados nominais de cada índice sob a ótica do investidor local, ou seja, sem ajuste cambial, durante o período de janeiro de 1998 até novembro de 2010. Fonte: CMA Trade. b Estatística t reportada com respectivo p-valor entre colchetes. Escolha de defasagens, segundo o critério de informação de Schwarz. c Estatística t ajustada reportada com respectivo p-valor entre colchetes. Seleção da largura das bandas a la Newey e West. d Estatística LM reportada. Seleção da largura das bandas a la Newey e West. e Estatística P reportada. Escolha de defasagens, segundo o critério de informação de Schwarz. f Resultado reportado considerando todos os testes modificados: Mza, Mzt, MSB e MPT. Escolha de defasagens, segundo o critério de informação de Schwarz. g Estatística t reportada. Escolha de defasagens, segundo o critério de informação de Schwarz, com limitação máxima de 4 defasagens. Valores críticos a $5 \%$ : $-5,08$ no teste em nível e $-4,93$ no teste em $1^{\text {a }}$ diferença. h Estatística t reportada. Escolha de defasagens, segundo o critério de informação de Schwarz. Especificação da shift function: dummy no teste em nível e impulso no teste em $1^{\text {a }}$ diferença. Valores críticos a 5\%: $-3,03$ no teste em nível e $-2,88$ no teste em $1^{\text {a }}$ diferença. * Rejeição da hipótese nula a $10 \%$. ${ }^{* *}$ Rejeição da hipótese nula a 5\%. ${ }^{* * *}$ Rejeição da hipótese nula a $1 \%$. 


\subsection{Cointegração das séries de retorno acumulado}

Os índices das principais bolsas de valores da América do Sul apresentam uma quebra estrutural e tendências estocásticas, com ordem de integração I(1). Assim, nesta subseção são apresentados os resultados da análise de cointegração multivariada baseada em Johansen et alii (2000), cujos valores críticos consideram a presença de uma dummy associada à quebra estrutural identificada em setembro de 2008, segundo a quantidade de defasagens definida em acordo com o critério de Schwarz. A especificação considera intercepto e tendência.

Os resultados do teste (Tabela 4) sugerem a existência de um único vetor de cointegrante a um nível de significância de $5 \%$ e consequentemente de cinco tendências estocásticas comuns e no máximo de um ciclo comum. Este resultado é robusto à mudança de teste, sendo a hipótese nula do teste de razão de verossimilhança de não cointegração rejeitada a $5 \%$ e a hipótese nula de 1 vetor cointegrante não rejeitada, mesmo a $10 \%$.

Tabela 4: Teste do traço de cointegração de Johansen et alii (2000)

\begin{tabular}{cccccc}
\hline \multirow{2}{*}{ HO } & LR & \multicolumn{3}{c}{ Valores Críticos } & p-valor \\
\cline { 3 - 4 } & & $90 \%$ & $95 \%$ & $99 \%$ & \\
\hline$r \leq 0$ & 129,65 & 120,95 & 126,04 & 135,98 & 0,029 \\
$r \leq 1$ & 80,20 & 91,42 & 95,88 & 104,65 & 0,377 \\
$r \leq 2$ & 49,68 & 65,87 & 69,72 & 77,32 & 0,665 \\
$r \leq 3$ & 27,06 & 44,32 & 47,54 & 53,97 & 0,852 \\
$r \leq 4$ & 14,81 & 26,95 & 29,17 & 34,42 & 0,778 \\
$r \leq 5$ & 6,14 & 12,50 & 14,40 & 18,43 & 0,617 \\
\hline
\end{tabular}

Teste de cointegração aplicado às séries de retornos acumulados nominais de cada índice sob a ótica do investidor local, ou seja, sem ajuste cambial, durante o período de janeiro de 1998 até novembro de 2010. Fonte: CMA Trade. b O teste inclui uma dummy referente à quebra estrutural na data de 2008.9 e utiliza uma defasagem de acordo com critério de Schwarz, considerando-se a presença de um intercepto e uma tendência. c Os valores críticos foram obtidos em Johansen et alii (2000).

O resultado da estimação dos parâmetros do vetor cointegrante, $Z_{t}$, está reportado a seguir, assumindo sem perda de generalidade, a normalização unitária no parâmetro associado ao índice brasileiro. ${ }^{8}$

$$
\begin{aligned}
& Z_{t}=1,00 . I B O V_{t}-0,83 . I G B C_{t}+4,05 . M E R V A L_{t}-1,10 . I B V C_{t}+0,31 . I G B V L_{t}-3,65 . I P S A_{t}+1,68 \\
& \begin{array}{llll}
(0,22) & (0,83) & (0,27) & (0,13)
\end{array}
\end{aligned}
$$

A metodologia proposta em Johansen et alii (2000) identifica o posto da matriz associada ao polinômio $\psi(1)$ e estima simultaneamente, via máxima verossimilhança, o vetor cointegrante, assim como o VECM em sua forma reduzida e restrita, considerando a quebra estrutural evidenciada (dummy). Seguem as estimações do VECM. ${ }^{9}$

\footnotetext{
${ }^{8} 0$ respectivo erro padrão da estimação via máxima verossimilhança está reportado entre parênteses.

${ }^{9}$ Segundo Vahid e Engle (1993), na ausência de uma rotina de verossimilhança, é possível estimar este arcabouço através da técnica 3SLS.
} 


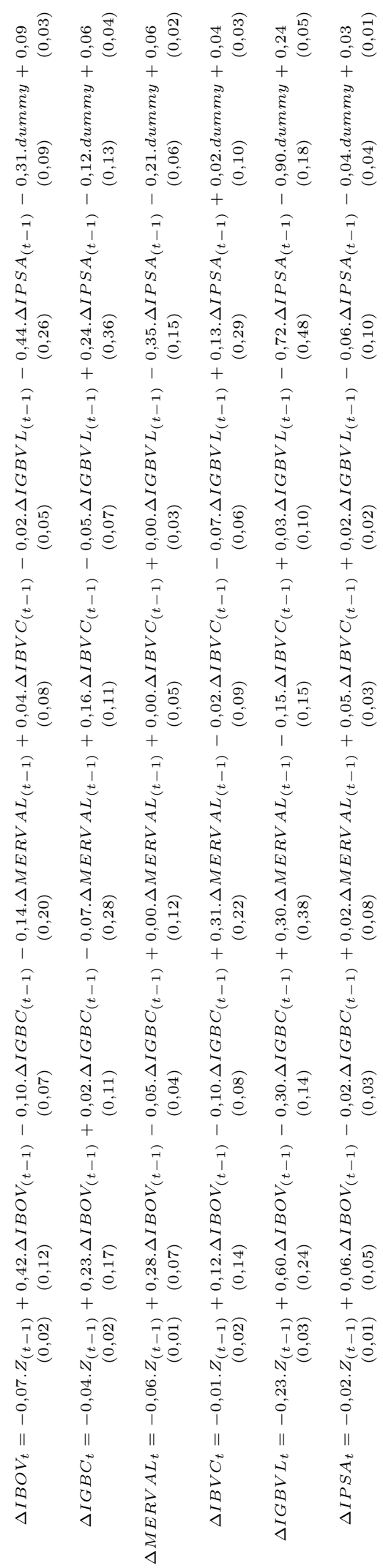




\subsection{Tendências e ciclos individuais das séries de retorno acumulado}

A evolução dos ciclos e tendências individuais para cada índice está na Figura 2. Uma análise apenas gráfica desta figura sugere que ao longo do período de estabilidade econômica mundial, especificamente entre 2001 e 2006, as bolsas dessas economias pareçam ser determinadas pelas tendências, de forma que sejam influenciadas mais pelos fundamentos econômicos domésticos do que por fatores financeiros idiossincráticos. Nos períodos de crise, há uma maior heterogeneidade nas reações aos choques, as quais passam a ter maior representatividade na decomposição do retorno acumulado. Outro aspecto comum aos índices do continente é a evidência de que as expansões transitórias possuem menor magnitude e persistência que as contrações, estas associadas aos ciclos comuns negativos. ${ }^{10}$

Figura 2: Evolução dos retornos acumulados e dos respectivos ciclos e tendências individuais dos índices de mercado dos países da América do Sul, incorporando a quebra estrutural identificada em setembro de 2008
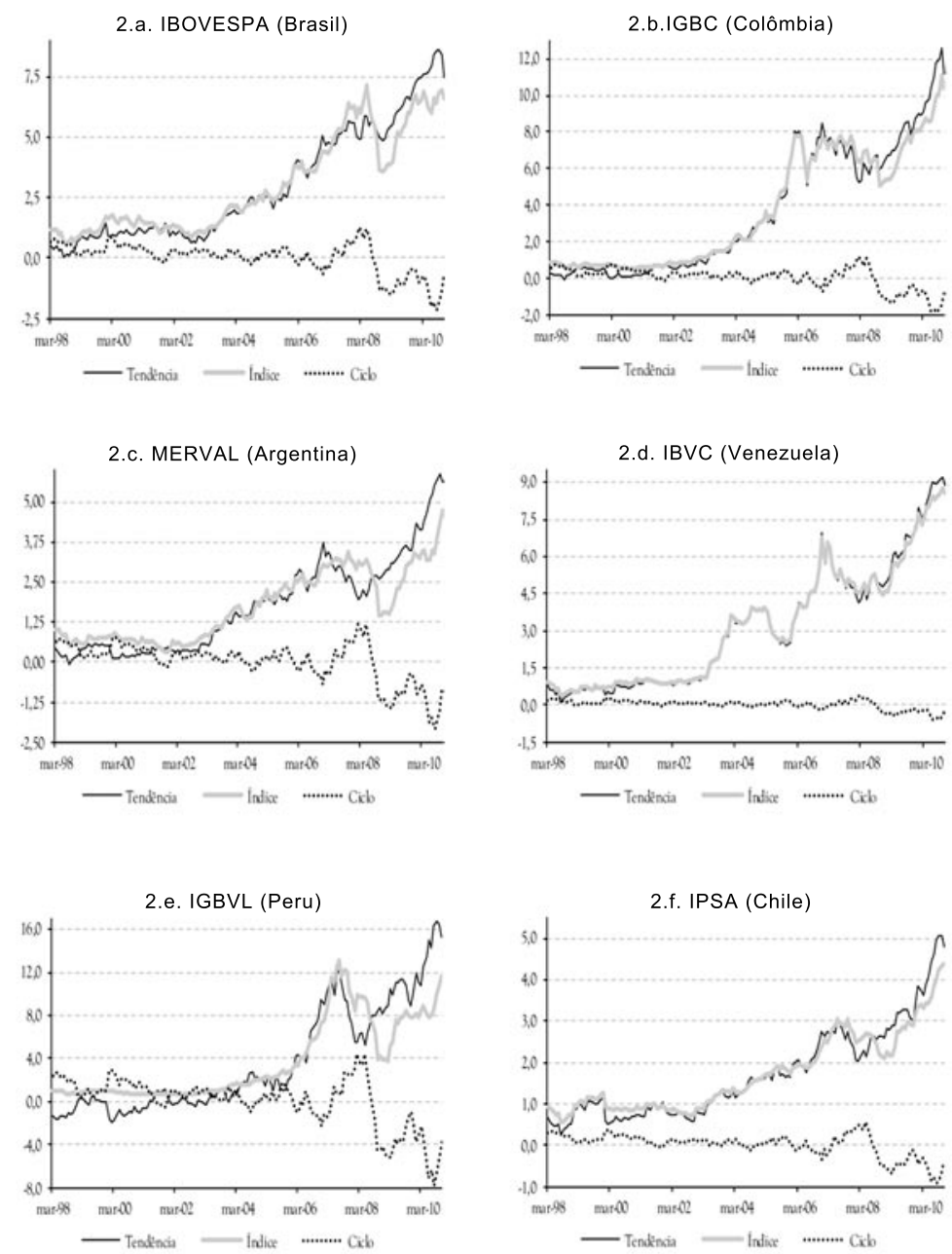

\footnotetext{
${ }^{10}$ Visando um resultado mais robusto baseado em inferência estatística, é possível analisar a decomposição da variância das séries em questão.
} 
Esses resultados corroboram as evidências e os argumentos teóricos reportados em D’ecclesia e Costantini (2006). Estes autores, ao analisarem empiricamente as tendências e ciclos comuns em cinco dos mais desenvolvidos mercados financeiros no mundo, sugerem que o efeito contágio, motivado no caso pelos canais de liquidez e rebalanceamento cross-country, seja mais evidente em razão de eventos extremos globais, positivos ou negativos, capazes de provocar oscilações de curto prazo mais acentuadas e em direções comuns, cenário que se observa quando do período a crise financeira iniciada em 2007. Já no longo prazo, as trajetórias são determinadas pelo componente estocástico na forma de um passeio aleatório, ou seja, as tendências individuais.

Cada ciclo individual, por estar associado a uma reação sob a forma de um choque, possui média estatisticamente nula. Mesmo considerando que a ordem de grandeza do ciclo dependa da magnitude do ganho acumulado do respectivo índice, visivelmente o ciclo individual do IGBVL apresenta comportamento mais volátil.

Durante os anos de 1999 e 2000, período posterior à crise russa e durante o qual o Brasil passava por dificuldades cambiais, os desvios entre o retorno e a respectiva tendência passam a apresentar valores sistematicamente positivos e com maior ordem de grandeza, exceto para os índices chileno e venezuelano, onde os choques individuais positivos são mais suaves.

No período que antecede ao estopim da crise de 2007, em todos os mercados em questão há dois distintos e evidentes períodos de choques negativos, havendo no segundo semestre de 2007 ciclos positivos com elevadas magnitudes que se sucedem até meados de 2008, quando a partir daí, se evidencia o período mais turbulento da crise e uma sucessão de choques negativos, cuja ordem de grandeza é comparável aos valores obtidos para as respectivas tendências. O período pós-crise é caracterizado pela persistência desses ciclos negativos, sugerindo recuperação financeira mais lenta que a prevista pelos fundamentos no continente.

As estatísticas descritivas das tendências e dos ciclos, individuais e comuns, são analisadas nas subseções 4.5 e 4.6 , respectivamente.

\subsection{Tendências comuns}

Os seis mercados financeiros sul-americanos estabelecem entre si uma relação de equilíbrio financeiro de longo prazo baseada em cinco tendências estocásticas comuns. A Figura 3 mostra a evolução das tendências comuns (3.a.) e individuais (3.b.), incorporando a quebra estrutural em setembro de 2008.

O fato de haver cinco tendências comuns, mesmo sendo distintas principalmente a partir de 2004, sugere que todas as trajetórias comuns sinalizem para cenários de desenvolvimento do mercado financeiro.

Há uma única possível trajetória comum, \#1, caracterizada por um forte deslocamento superior, a qual não incorpora as quedas que todos os índices experimentaram com a crise financeira, sugerindo a permanência de uma trajetória crescente e estável de sustentabilidade econômica. As demais trajetórias comuns sugerem que os países da América do Sul sigam fontes de risco essencialmente negativos durante a crise, principalmente com base na tendência comum \#5 - a qual se descola inferiormente a partir de 2006 e atinge o menor patamar ao final de 2007 -, com posterior recuperação financeira agregada dos mercados sul-americanos.

Observando a Figura 3.b, evidencia-se que as tendências individuais são comparáveis entre si, havendo tanto um patamar médio, como níveis de oscilação cujos valores são inferiores para os índices chileno e argentino. A tendência individual do índice peruano aparece como a mais volátil dentre as demais tendências individuais, oscilando menos que a tendência comum \#1, apenas.

Apesar da heterogeneidade ao longo do período compreendido entre 2007 e 2008, as tendências dos índices possuem elevadas correlações positivas, todas superiores a 0,92 , enquanto a análise das tendências comuns permite inferir que as tendências \#2 e \#4 sejam as mais correlacionadas entre si e a tendência comum \#5 seja negativamente correlacionada com as demais tendências comuns, 
assim como com as individuais. Assim como a tendência comum \#1, a qual se correlaciona quase perfeitamente com todos os índices, as tendências \#2 e \#4 também apresentam elevadas correlações positivas, da ordem de 0,7 e 0,8 . A tendência comum \#3 apresenta correlações com as tendências individuais ainda positivas, porém com menores valores.

Figura 3: Evolução das tendências comuns (3.a.) e das tendências individuais (3.b.) dos índices de mercado dos países da América do Sul, incorporando a quebra estrutural identificada em setembro de 2008.

3.a. Tendências comuns

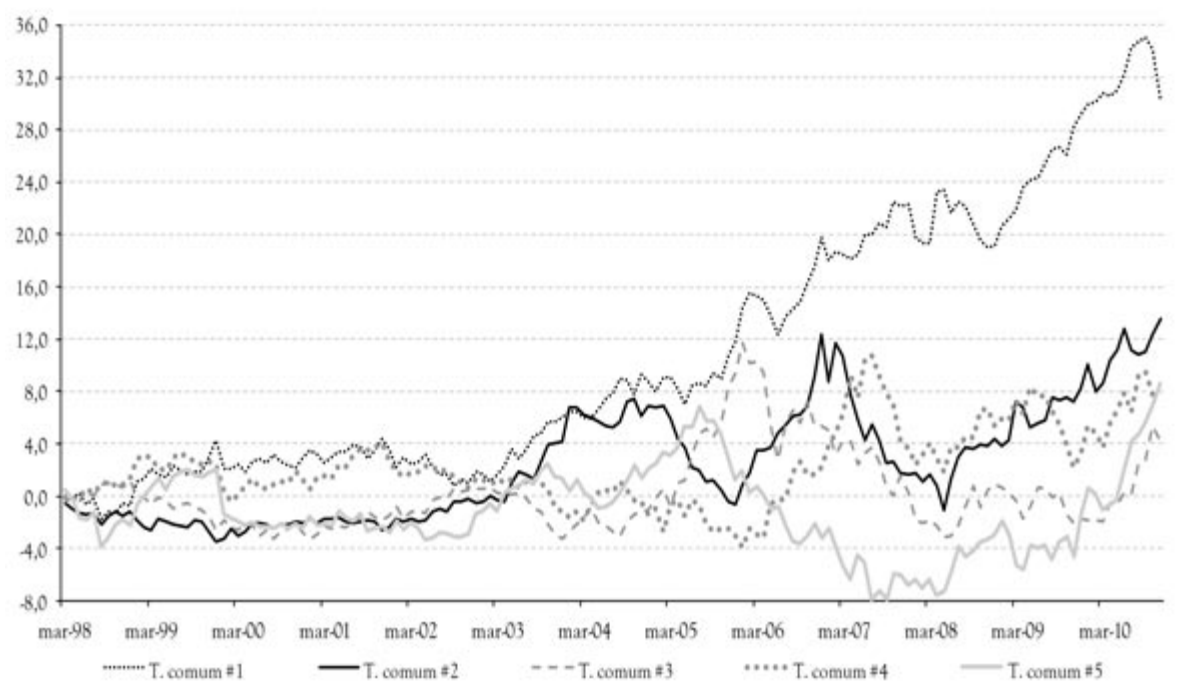

3.b. Tendências individuais

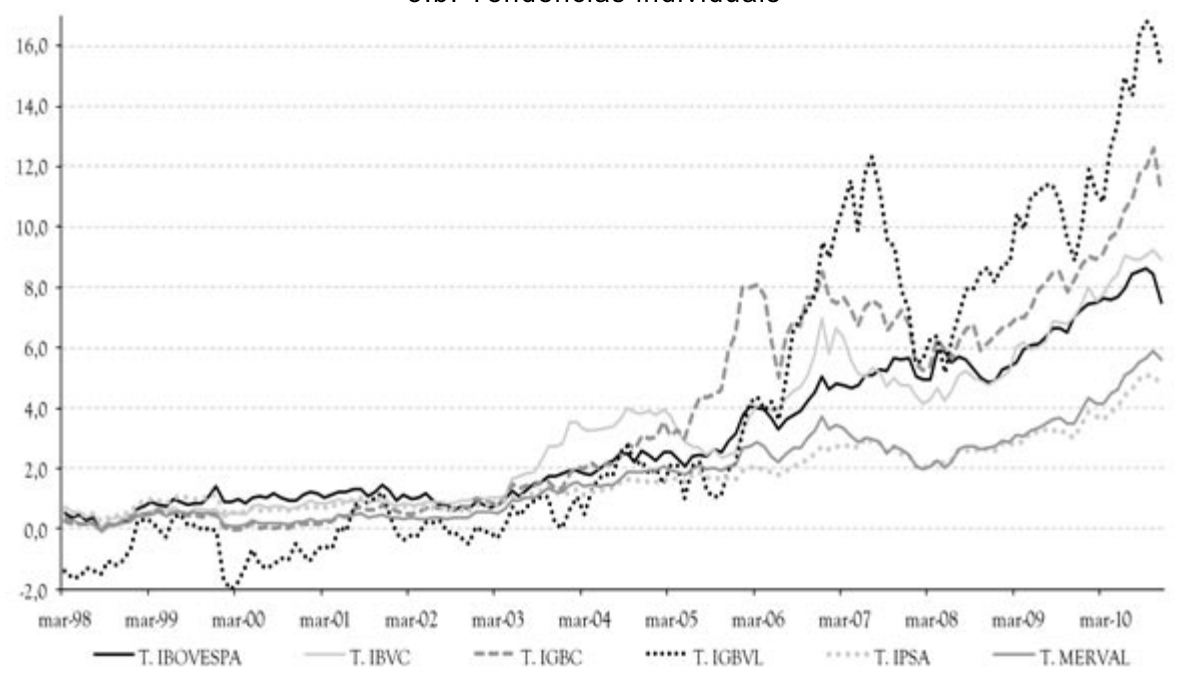




\subsection{Ciclos Comuns}

Seguindo Vahid e Engle (1993), os resultados da análise conjunta dos mercados financeiros da América do Sul no curto prazo, incorporando a quebra estrutural de setembro de 2008, sinalizam para a presença de um único comportamento cíclico comum. Mais especificamente, observa-se uma estatística LR no valor de 35,99, que em um teste com 30 graus de liberdade, sugere que a hipótese nula de haver pelo menos um ciclo comum nos retornos dos índices de mercado na América do Sul não deva ser rejeitada a $5 \%$ de significância. Os resultados obtidos para todas as possíveis quantidades de ciclos comuns estão reportados na Tabela 5.

Tabela 5: Teste de Vahid e Engle (1993) de ciclos comuns

\begin{tabular}{cccc}
\hline $\mathrm{N}^{0}$ de Ciclos Comuns & Estatística LR & Graus de liberdade & $\mathrm{p}$-valor \\
\hline 1 & 35,99 & 30 & 0,208 \\
2 & 17,93 & 20 & 0,592 \\
3 & 9,66 & 12 & 0,646 \\
4 & 3,83 & 6 & 0,700 \\
5 & 1,82 & 2 & 0,402 \\
\hline
\end{tabular}

Rotina proposta em Warne (2008) aplicada às séries considerando a quebra estrutural em setembro de 2008.

Os ciclos individuais e o único ciclo comum estão descritos na Figura 4. Assim como na análise de tendências, os ciclos individuais e o comum são comparáveis parecendo possuir padrões similares ao longo do tempo, sendo possível observar que o ciclo comum apresenta comportamento mais volátil que a maioria dos ciclos individuais, sendo comparável ao ciclo individual do IGBVL, cuja volatilidade é de 2,323, mensurada pelo desvio padrão. Os valores destes dois ciclos estão reportados no eixo direito da figura, em razão da ordem de grandeza. Os demais ciclos individuais possuem volatilidade que oscilam entre 0,188, para o IBVC e 0,650 do IBOVESPA. Em termos de valores extremos, o menor dos valores obtidos para os ciclos é observado ao final do período para o ciclo comum, $-9,273$, enquanto o valor máximo de 4,413 é identificado para o IGBVL no primeiro semestre de 2008.

Figura 4: Evolução dos ciclos individuais e comum dos índices de mercado dos países da América do Sul, incorporando a quebra estrutural identificada em setembro de 2008.

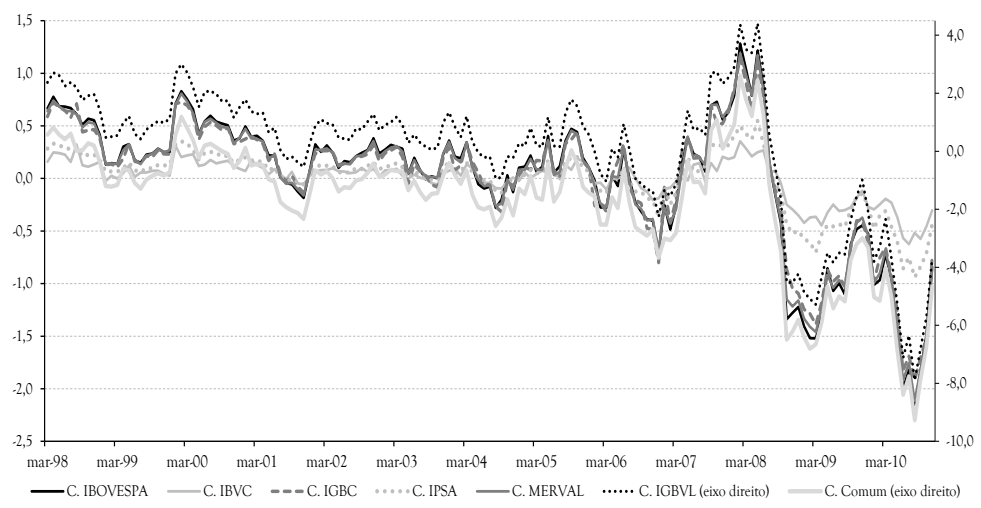


As estatísticas dos ciclos estão reportadas na Tabela 6. Segundo o painel A desta tabela, os ciclos individuais de todos os índices se correlacionam positivamente de forma muito robusta, sendo possível concluir de acordo com este modelo, que o sentido dos movimentos de curto prazo causados por choques transitórios são os mesmos nos seis índices, porém, com intensidades diferentes. As correlações entre cada ciclo individual e o comum oscilam entre 0,750 e 0,786 , com os índices brasileiro, argentino e peruano apresentando os mais elevados valores de correlação. Estas elevadas correlações positivas entre os ciclos individuais, assim como a existência de um único ciclo comum aqui não devem ser vistas como uma evidência do baixo poder de diversificação no curto prazo por parte de um investidor interessado em portfolios com índices das economias sul americanas, pois as séries aqui utilizadas não incorporam a questão do risco cambial, consistindo na evolução do valor de mercado agregado das principais empresas de capital aberto em cada um dos países, sob a ótica do respectivo investidor local. ${ }^{11}$

Tabela 6: Características dos ciclos individuais e comum dos índices de mercado dos países da América do Sul a, b

\begin{tabular}{|c|c|c|c|c|c|c|c|}
\hline \multicolumn{8}{|c|}{ Painel A: Correlação entre os ciclos individuais e o ciclo comum } \\
\hline Ciclos & Comum & IBOVESPA & IBVC & IGBC & IGBVL & IPSA & MERVAL \\
\hline Comum & 1,000 & & & & & & \\
\hline IBOVESPA & 0,786 & 1,000 & & & & & \\
\hline IBVC & 0,750 & 0,964 & 1,000 & & & & \\
\hline IGBC & 0,777 & 0,993 & 0,973 & 1,000 & & & \\
\hline IGBVL & 0,786 & 0,997 & 0,963 & 0,991 & 1,000 & & \\
\hline IPSA & 0,781 & 0,994 & 0,965 & 0,996 & 0,997 & 1,000 & \\
\hline MERVAL & 0,786 & 0,999 & 0,965 & 0,995 & 0,999 & 0,997 & 1,000 \\
\hline \multicolumn{8}{|c|}{ Painel B: Estatísticas descritivas dos ciclos } \\
\hline Ciclos & Comum & IBOVESPA & IBVC & IGBC & IGBVL & IPSA & MERVAL \\
\hline M?dia & $-1,711$ & $2,89 \mathrm{E}-09$ & $-1,88 \mathrm{E}-08$ & $1,20 \mathrm{E}-08$ & $8,61 \mathrm{E}-09$ & $1,24 \mathrm{E}-08$ & $-3,03 \mathrm{E}-08$ \\
\hline Desvio padrão & 2,197 & 0,650 & 0,188 & 0,591 & 2,323 & 0,281 & 0,627 \\
\hline Mínimo & $-9,273$ & $-2,161$ & $-0,625$ & $-1,915$ & $-7,897$ & $-0,940$ & $-2,114$ \\
\hline Máximo & 2,595 & 1,283 & 0,354 & 1,148 & 4,413 & 0,547 & 1,192 \\
\hline
\end{tabular}

Painel C: Causalidade de Granger entre os ciclos individuais c

\begin{tabular}{|c|c|c|c|c|c|c|}
\hline Causalidade & IBOVESPA & IBVC & IGBC & IGBVL & IPSA & MERVAL \\
\hline IBOVESPA & & $\mathrm{F}=101,116[0,000]^{*}$ & $\mathrm{~F}=7,818[0,006]^{*}$ & $\mathrm{~F}=0,230[0,632]$ & $\mathrm{F}=4,530[0,034]^{*}$ & $F=0,108[0,742]$ \\
\hline IBVC & $\mathrm{F}=0,211[0,647]$ & & $F=0,423[0,516]$ & $\mathrm{F}=0,738[0,392]$ & $\mathrm{F}=0,020[0,889]$ & $F=0,531[0,468]$ \\
\hline IGBC & $\mathrm{F}=0,224[0,637]$ & $\mathrm{F}=85,827[0,000]^{*}$ & & $F=0,001[0,974]$ & $F=0,013[0,908]$ & $F=0,265[0,607]$ \\
\hline IGBVL & $\mathrm{F}=8,072[0,005]^{*}$ & $\mathrm{~F}=100,456[0,000]^{*}$ & $\mathrm{~F}=12,442[0,001]^{*}$ & & $\mathrm{~F}=10,469[0,002]^{*}$ & $\mathrm{~F}=4,637[0,033]^{*}$ \\
\hline IPSA & $F=1,246[0,266]$ & $\mathrm{F}=93,811[0,000]^{*}$ & $\mathrm{~F}=4,755[0,031]^{*}$ & $F=0,179[0,673]$ & & $F=0,027[0,871]$ \\
\hline MERVAL & $F=2,963[0,087]$ & $\mathrm{F}=105,135[0,000]^{*}$ & $\mathrm{~F}=9,909[0,002]^{*}$ & $F=0,291[0,590]$ & $\mathrm{F}=6,355[0,013]^{*}$ & \\
\hline
\end{tabular}

Painel D: Causalidade de Granger entre cada ciclo individual e o ciclo comum

\begin{tabular}{|c|c|c|c|c|c|c|}
\hline Causalidade & IBOVESPA & IBVC & IGBC & IGBVL & IPSA & MERVAL \\
\hline C. Comum $->C$. Individual & $\mathrm{F}=2,877[0,092]$ & $\mathrm{F}=98,332[0,000]^{*}$ & $\mathrm{~F}=10,465[0,002]^{*}$ & $\mathrm{~F}=0,003[0,954]$ & $\mathrm{F}=7,082[0,009]^{*}$ & $\mathrm{~F}=0,799[0,373]$ \\
\hline C. Individual $->$ C. Comum & $F=0,011[0,916]$ & $F=0,216[0,643]$ & $F=1,638[0,203]$ & $\mathrm{F}=5,359[0,022]^{*}$ & $\mathrm{~F}=1,979[0,161]$ & $F=1,257[0,264]$ \\
\hline
\end{tabular}

Por serem próximos os valores das correlações, caracterizando um comportamento similar dentre estas bolsas, analisa-se a influência dos ciclos individuais no ciclo comum em termos preditivos, cujos resultados estão reportados no painel D da Tabela 6. Atendo-se ao teste de causalidade proposto em

\footnotetext{
${ }^{11}$ Sobre esta questão de diversificação, segundo Azevedo et alii (2013), ao se analisar empiricamente o home bias puzzle sob a ótica de um investidos doméstico brasileiro, dentre várias carteiras sugeridas, a única capaz de justificar uma estratégia baseada na diversificação internacional para um agente brasileiro seria composta pelos índices de mercado da América do Sul, com composição equal weighted.
} 
Granger (1969) e amplamente divulgada em Sims (1972), com um lag das variáveis em questão, o ciclo comum é relevante na previsão somente dos ciclos individuais chileno, colombiano e venezuelano. 0 IGBVL aparece como o único capaz de prever o ciclo comum, corroborando a evidência de que a resposta a estímulos de curto prazo do mercado financeiro peruano seja a de maior peso na definição de como responderá o conjunto das bolsas da América do Sul. A análise das causalidades entre os ciclos individuais (Painel C) sugere uma possível trajetória na condução do contágio, segundo a qual, o índice peruano é o único capaz de causar todos os demais ciclos individuais, não sendo previsto por nenhum deles. Os ciclos dos índices brasileiro e argentino, previstos pelo ciclo peruano, se mostram úteis na previsão de todos os três demais. $O$ índice IPSA do Chile influencia os ciclos dos índices colombiano e venezuelano. Os choques na Venezuela são previsíveis por todos os demais ciclos individuais.

o que poderia estar associado a esta capacidade preditiva da reação do sistema financeiro peruano frente aos principais mercados da América do Sul? Apesar de ser necessário responder a tal questionamento a partir de inferência estatística, parece útil uma simples contextualização da economia e da bolsa de valores deste país.

Comparado aos demais países da amostra, esta economia possui o menor PIB per capita expresso em US\$ de 2009 sob paridade de poder de compra, \$8.629,00, segundo o Banco Mundial (2010), o que parece estar sendo visto com otimismos por analistas os quais acreditam haver um forte potencial de crescimento e desenvolvimento deste país, apesar do ambiente político instável. O que se observa a partir de 2005 é um crescimento econômico médio superior a $6 \%$ ao ano, sendo citados dentre as mais relevantes aspectos: o aumento acompanhado de uma maior diversidade dos acordos de livre comércio com a União Europeia e China e a variação positiva dos preços das commodities. Segundo o mais recente boletim de Sondagem Econômica da América Latina, da Fundação Getulio Vargas de 2011, o Peru apresentou o melhor índice de clima econômico em 2010, atingindo 6,2 pontos.

A contrapartida deste cenário macroeconômico favorável no sistema financeiro peruano pode ser caracterizada pela integração das bolsas dos três países andinos, passando a ser a $2^{\mathrm{a}}$ da América do Sul em volume financeiro negociado diariamente e em valor de mercado, atrás apenas da bolsa brasileira, conforme dados da Consultoria Economatica. Segundo esta mesma fonte, o valor de mercado após a fusão será de quase US\$ 600 bilhões, dos quais aproximadamente $1 / 6$ deriva da participação da economia peruana, onde aproximadamente 100 empresas possuem ações sendo transacionadas. Esta realidade econômico-financeira do Peru pode estar sendo refletida nos números, segundo os quais, o IGBVL obteve ganho acumulado superior a $1.060 \%$ durante o período analisado e máxima queda a acumulada de quase $72 \%$, valores bastante superiores quando comparados aos observados nos demais países da amostra. Já com base nos resultados, o ciclo individual do índice peruano, assim como sua tendência são os que apresentam maior volatilidade do continente, com destaque para a maior média na tendência individual, a qual apresenta os valores extremos, máximo e mínimo, com maior ordem de grandeza.

\subsection{Extensão amostral do estudo}

Em Bueno (2011) há uma discussão interessante sobre a limitação na análise feita quando do uso de Causalidade no sentido de Granger. Inicialmente, por ser um exercício de previsão em um arcabouço linear sugere-se usar variáveis estacionárias, como os ciclos, no caso. Porém, o mais importante está na conclusão econômica ou financeira de que um ciclo causa outro, quando, em razão da possibilidade de variáveis omitidas que causam ambos os ciclos, tal afirmação seja espúria. Este é um argumento especialmente válido quando do estudo de relações de curto prazo em uma amostra composta apenas por economias emergentes, uma vez que é possível haver um relevante índice de mercado de uma economia desenvolvida, omitido do estudo a priori, o qual poderia estar sendo o responsável pelas causalidades observadas.

Apesar de ter sido uma amostra de países escolhida criteriosamente, havendo prévias evidências de convergência neste continente e sendo o canal de contágio via assimetria justificado entre países emergentes com fortes laços econômicos, uma forma de lidar com este aspecto seria implementar um novo 
exercício inserindo mercados financeiros desenvolvidos. Neste sentido, diante das inúmeras extensões amostrais possíveis e visando obter robustez aos resultados reportados no artigo, implementa-se um segundo exercício com a inserção de um sétimo índice de mercado, o Standard na Poor’s 500, S\&P500. Este é um índice I(1), cuja metodologia data de 1957 e cuja composição é ponderada pela capitalização de mercado das ações. A escolha deste índice segue uma extensa literatura de finanças empíricas, de Mehra e Prescott (1985) a Fama e French (2010), a qual adota este índice como benchmark de carteira de mercado do sistema financeiro americano.

Em suma, este segundo exercício corrobora as principais evidências aqui já reportadas. É possível observar que há um vetor cointegrante nessa nova amostra, com uma tendência comum adicional e um único ciclo comum. A análise detalhada dos ciclos comum e individuais permite inferir que o sistema financeiro americano não parece ser o responsável pelo contágio evidenciado na América do Sul. O S\&P500 não é estatisticamente relevante na previsão do ciclo comum, nem da maioria dos ciclos individuais. Apenas os ciclos individuais colombiano e venezuelano, ambos previsíveis por todos os demais ciclos individuais no primeiro exercício empírico, se mostram previsíveis pelo ciclo individual americano. Este ciclo individual, por sua vez, está sujeito à causalidade de Granger do ciclo comum e dos ciclos individuais dos sistemas financeiros brasileiro, argentino, colombiano e peruano, a um nível de 5\%. A um nível de significância de 10\%, até o ciclo chileno Granger causa o ciclo do S\&P500.

\section{CONCLUSÃO}

Este artigo agrega à discussão sobre integração e contágio financeiro nos países da América do Sul, um continente caracterizado pela diversidade em seus fundamentos macroeconômicos e financeiros que experimenta há meio século inócuas tentativas de constituição de blocos comerciais e monetários.

A evidência aqui obtida, seguindo metodologicamente Johansen et alii (2000), corrobora os resultados reportados em Mejía-Reyes (2000), Hecq (2001) e Matos e Landim (2011), sugerindo que haja equilíbrio de longo prazo caracterizado por tendências com inclinação positiva, se considerado todo o intervalo de tempo, determinada por fundamentos, como desenvolvimento econômico-financeiro e inovação tecnológica. A hipótese nula de elevado nível de contágio financeiro entre estes índices não deve ser rejeitada, havendo, segundo os resultados obtidos a partir da metodologia desenvolvida em Vahid e Engle (1993), elevadas correlações entre os ciclos, com forte influência preditiva do ciclo do índice peruano em todos os ciclos, individuais e comum.

\section{BIBLIOGRAFIA}

Allen, F., Chui, M., \& Maddaloni, A. (2004). Financial systems in Europe, the USA and Asia. Oxford Review of Economic Policy, 20:490-508.

Allen, F. \& Gale, D. (2000). Financial contagion. The Journal of Political Economy, 108:1-33.

Antzoulatos, A., Panopoulou, E., \& Tsoumas, C. (2011). Do financial systems converge? Review of International Economics, 19:122-136.

Azevedo, A., Matos, P., \& Lacerda, Y. (2013). O Poder de Diversificação Internacional de um Investidor Brasileiro: Hermanos, Yes, We Can! Working paper, CAEN/ UFC.

Banco Mundial (2010). World development indicators 2010. Washington, DC.

Banerjee, A., Lumsdaine, R., \& Stock, J. (1992). Recursive and Sequential Tests for a Unit Root: Theory and International Evidence. Journal of Business \& Economic Statistics, 10:271-287. 
Beveridge, S. \& Nelson, C. (1981). A new approach to decomposition of economic time series into permanent and transitory components with particular attention to measurement of the business cycle. Journal of Monetary Economics, 7:151-174.

Bianco, M., Gerali, A., \& Massaro, R. (1997). Financial systems across developed economies: convergence or path dependence? Research in Economics, 51:303-331.

Bueno, R. (2011). Econometria de Séries Temporais. Cencage Learning.

Candelon, B. \& Lutkepohl, H. (2001). On the reliability of Chow-type tests for parameter constancy in multivariate dynamic models. Economics Letters, 73:155-160.

Chan-Lau, J., Donald, M., \& Yao, J. (2004). Extreme Contagion in Equity Markets. IMF Staff Papers, 51:386-408.

Christiano, L. . (1992). Searching for a Break in GNP. Journal of Business \& Economic Statistics, 10:237-250.

Claessens, S. \& Forbes, K. (2004). International Financial Contagion: The Theory, Evidence and Policy Implications. Paper presented at the conference IMF's Role in Emerging Market Economies: Reassessing the Aequacy of its Resources, Amsterdam.

D'ecclesia, R. \& Costantini, M. (2006). Comovements and correlations in international stock markets. The European Journal of Finance, 12:567-582.

Dempster, G., Wells, J., \& Wills, D. (2000). A common-features analysis of Amsterdam and London financial markets during the eighteenth century. Economic Inquiry, 38:19-33.

Dickey, D. \& Wayne, F. (1979). Distribution of the estimators for autoregressive time series with a unit root. Journal of the American Statistical Association, 74:427-431.

Dickey, D. \& Wayne, F. (1981). Likelihood ratio statistics for autoregressive time series with a unit root. Econometrica, 49:1057-1072.

Elliott, G., Rothenberg, T., \& Stock, J. (1996). Efficient tests for an autoregressive unit root. Econometrica, 64:813-836.

Enders, W. (2010). Applied econometric time series. Wiley Series in Probability and Statistics.

Engle, R. (1997). Trends, cycles and autoregressions. The Economic Journal, 107:192-201.

Engle, R. \& Granger, C. (1987). Cointegration and error correction: representation, estimations and testing. Econometrica, 55:251-266.

Engle, R. \& Kozicki, S. (1993). Testing for common features. Journal of Business and Economic Statistics, 11:369-379.

Evans, G. (1989). Output and unemployment dynamics in the United States: 1950-1985. Journal of Applied Econometrics, 4:213-237.

Fama, E. \& French, K. (2010). Luck versus skill in the cross-section of mutual fund returns. The Journal of Finance, 65:1915-1947.

Fürstenberg, G. \& Jeon, B. (1989). International stock price movements: links and messages. Brooking papers on Economic Activity, 1:125-179.

Gourieroux, C., Monfort, A., \& Renault, E. (1991). A general framework for factor models. Technical report, INSEE 9107. 
Granger, C. (1969). Investigating causal relations by econometric models and cross-spectral methods. Econometrica, 37:424-438.

Hecq, A. (2001). Common Cycles and Common Trends in Latin America. Working paper, University of Maastricht.

Hecq, A., Palm, F., \& Urbain, J. (2000). Comovements in international stock markets. what can we learn from a common trend-common cycle analysis. De Economist, 148:395-406.

Henry, P. (2007). Capital account liberalization: theory, evidence, and speculation. Journal of Economic Literature, 45:887-935.

Issler, J. \& Vahid, F. (2001). Common cycles and the importance of transitory shocks to macroeconomic aggregates. Journal of Monetary Economics, 47:449-475.

Johansen, S., Mosconi, R., \& Nielsen, B. (2000). Cointegration analysis in the presence of structural breaks in the deterministic trend. Econometrics Journal, 3:216-249.

Kose, M., Prasad, E., Rogoff, K., \& Wei, S. (2006). Financial globalization: a reappraisal. Working Paper 189, International Monetary Fund.

Kwiatkowski, D., Phillips, P., Schmidt, P., \& Shin, Y. (1992). Testing the null hypothesis of stationarity against the alternative of a unit root: How sure are we that economic time series have a unit root? Journal of Econometrics, 54:159-178.

Leybourne, S., Newbold, P., \& Vougas, D. (1998). Unit roots and smooth transitions. Journal of Time Series Analysis, 19:83-97.

Matos, P. P. C. \& Landim, M. (2011). Análise de convergência de performance das bolsas de valores: a situação do Ibovespa no cenário mundial. Revista Brasileira de Finanças, 9:437-459.

Mehra, R. \& Prescott, E. (1985). The equity premium: a puzzle. Journal of Monetary Economics, 15:627636.

Mejía-Reyes, P. (2000). Asymmetries and Common Cycles in Latin America: Evidence from MarkovSwitching Models. Economia Mexicana Nueva Época, 9:189-225.

Morley, B. \& Pentecost, E. (2000). Common trends and cycles in G-7 countries exchange rates and stock prices. Applied Economic Letters, 7:7-10.

Park, J. \& Sung, J. (1994). Testing for unit roots in models with structural change. Econometric Theory, 10:917-936.

Perron, P. (1989). The Great Crash, the Oil Price Shock and the Unit Root Hypothesis. Econometrica, 57:1361-1401.

Perron, P. \& Ng, S. (1996). Useful modifications to some unit root tests with dependent errors and their local asymptotic properties. Review of Economic Studies, 63:435-463.

Perron, P. \& Vogelsang, T. (1991). The Great Crash, the Oil Price Shock and the Unit Root Hypothesis: Corrections and Extensions of Some Asymptotic Results. Unpublished manuscript, Princeton University, Dept. of Economics.

Phillips, P. \& Perron, P. (1988). Testing for a unit root in time series regression. Biometrika, 75:335-346. 
Phillips, P. \& Sul, D. (2007). Transition modeling and econometric convergence tests. Econometrica, 75:1771-1855.

Proietti, T. (1997). Short-run dynamics in cointegrated systems. Oxford Bulletin of Economics and Statistics, 59:405-422.

Schmidt, R., Hackethal, A., \& Tyrell, M. (2001). The convergence of financial systems in Europe. Working Paper Series: Finance and Accounting 75, Johann Wolfgang Goethe-Universitat.

Sharma, S. \& Wongbangpo, P. (2002). Long-term trends and cycles in Asian stock markets. Review of Financial Economics, 11:299-315.

Sims, C. (1972). Money, income, and causality. American Economic Review, 65:540-552.

Stock, J. \& Watson, M. (1988). Testing for common trends. Journal of the American Statistical Association, 83:1097-1107.

Vahid, F. \& Engle, R. (1993). Common trends and common cycles. Journal of Applied Econometrics, 8:341360.

Warne, A. (2008). Estimation and Testing for Common Cycles. Working Paper.

Westermann, F. (2002). Stochastic trends and cycles in national stock markets indices: evidence from the U.S., the U.K. and Switzerland. Working paper, Center for Economic Studies of University of Munich. 